\title{
Standard Population
}

National Cancer Institute

\section{Source}

National Cancer Institute. Standard Population. NCI Thesaurus. Code C71556.

A population for a geographic area, such as the U.S. or the world, represented as a table giving the proportions of the population falling into different age groups. 